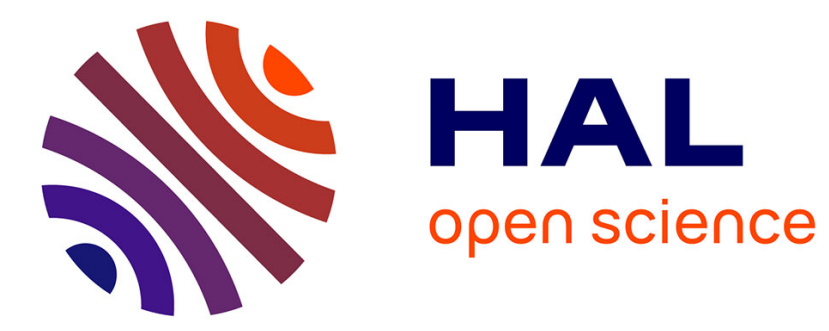

\title{
Investigating seasonality and season of birth in past herds: A reference set of sheep enamel stable oxygen isotope ratios
}

Marie Balasse, Gaël Obein, Joël Ughetto-Monfrin, Ingrid Mainland

\section{To cite this version:}

Marie Balasse, Gaël Obein, Joël Ughetto-Monfrin, Ingrid Mainland. Investigating seasonality and season of birth in past herds: A reference set of sheep enamel stable oxygen isotope ratios. Archaeometry, 2012, 54 (2), pp.349-368. 10.1111/j.1475-4754.2011.00624.x . hal-00744957v2

\section{HAL Id: hal-00744957 \\ https://hal.science/hal-00744957v2}

Submitted on 8 May 2019

HAL is a multi-disciplinary open access archive for the deposit and dissemination of scientific research documents, whether they are published or not. The documents may come from teaching and research institutions in France or abroad, or from public or private research centers.
L'archive ouverte pluridisciplinaire HAL, est destinée au dépôt et à la diffusion de documents scientifiques de niveau recherche, publiés ou non, émanant des établissements d'enseignement et de recherche français ou étrangers, des laboratoires publics ou privés. 


\title{
INVESTIGATING SEASONALITY AND SEASON OF BIRTH IN PAST HERDS: A REFERENCE SET OF SHEEP ENAMEL STABLE OXYGEN ISOTOPE RATIOS*
}

\author{
M. BALASSE, ${ }^{1}$ G. OBEIN,${ }^{2}$ J. UGHETTO-MONFRIN ${ }^{1}$ and I. MAINLAND ${ }^{3}$ \\ ${ }^{1}$ Muséum national d'Histoire naturelle USM 303 / CNRS UMR 7209 'Archéozoologie, Archéobotanique: Sociétés, Pratiques \\ et Environnements', Département Ecologie et Gestion de la Biodiversité, case postale 56, 55 rue Buffon, 75005 Paris, France \\ ${ }^{2}$ Laboratoire Commun de Métrologie LNE-CNAM, 61 rue du Landy, 93210 La Plaine St Denis, France \\ ${ }^{3}$ Department of Archaeology, University of the Highlands and Islands, Kirkwall, Orkney, KW15 1LX, UK
}

\begin{abstract}
Intra-tooth sequential analysis of enamel $\delta^{18} O$ is currently used to investigate birth seasonality in past animal populations, offering new insights into seasonal availability of animal resources, herd management and seasonality of site occupation. Reference data sets are still required to address two major difficulties: (1) that inter-individual variability in the record of the seasonal cycle is affected by tooth size; and (2) that the season of birth cannot be directly estimated from the timing of tooth growth, because of a delay in enamel mineralization. We present a data set acquired on the lower second molar of 10 modern sheep from Rousay (Orkney) born within a few weeks of each other in April/May and submitted to the same environmental conditions until death. All sheep have recorded a sinusoidal pattern of $\delta^{18} O$ variation spanning approximately a year. From the difference between the expected and the measured time sequence, the delay of enamel mineralization is estimated to be 5-6 months. The data set is then described using a model mainly based on a cosine function. The period, corresponding to the length of the M2 crown formed over a year, averaged $35.8 \mathrm{~mm}$. A very slight variation of tooth growth rate with time and no attenuation of the isotopic signal towards the cervical margin of the crown could be detected in this data set. The lowest $\delta^{I 8} \mathrm{O}$ values, corresponding to the sheep's first winter, were tracked at a distance from the enamel/ root junction that varied between 23.0 and $30.3 \mathrm{~mm}\left(x_{\min }\right.$ mean $\left.=27.6 \mathrm{~mm}\right)$; the highest $\delta^{18} \mathrm{O}$ values, corresponding to the sheep's second summer, were between 6.3 and $11.6 \mathrm{~mm}\left(x_{\max }\right.$ mean $=9.9 \mathrm{~mm}$ ). Most of the variability can be attributed to tooth size. When normalized on the period, $x_{\min }$ and $x_{\max }$ are $0.28( \pm 0.05)$ and $0.78( \pm 0.05)$ on average, meaning that the Rousay sheep have recorded the minimum and maximum $\delta^{18} O$ values on average at $78 \%$ and $28 \%$, respectively, of the end of the periodic cycle recorded in the second molar.
\end{abstract}

KEYWORDS: SHEEP, SEASONALITY OF BIRTH, $\delta^{18} \mathrm{O}$, TOOTH ENAMEL, ORKNEY

\section{INTRODUCTION}

Intra-tooth sequential analysis of enamel stable oxygen isotope composition $\left(\delta^{18} \mathrm{O}\right)$ is currently used to investigate birth seasonality in past animal populations (Balasse et al. 2003; Nelson 2005; Balasse and Tresset 2007; Britton et al. 2009; Henton et al. 2010). In terrestrial mammals, the stable oxygen isotope composition of enamel mineral (hydroxylapatite, hereafter referred to as bioapatite) is closely linked to that of meteoric precipitation (Land et al. 1980; Longinelli 1984; Luz et al. 1984; Kohn et al. 1996). Precipitation $\delta^{18} \mathrm{O}$ varies seasonally with ambient temperature at high and middle latitudes (Gat 1980; Rozanski et al. 1993). These 
seasonal changes are tracked in tooth mineral during growth, resulting in variability in the $\delta^{18} \mathrm{O}$ of bioapatite within a tooth row (Bryant et al. 1996a,b; Fricke and O'Neil 1996) and within a tooth (Koch et al. 1989, 1995; Fricke and O'Neil 1996; Stuart-Williams and Schwarcz 1997; Kohn et al. 1998; Sharp and Cerling 1998; Sharma et al. 2004; Nelson 2005; Bernard et al. 2009; van Dam and Reichart 2009). Because the timing of tooth growth is fixed within a species, distinct patterns of variation in enamel $\delta^{18} \mathrm{O}$ within tooth rows reflect different seasons of birth, as exposed for the first time by Bryant et al. (1996a,b) in their studies of fossil populations of equids. When tooth growth spans several seasons, birth seasonality can be investigated with a higher time resolution at the scale of a tooth, through sequential sampling (Balasse et al. 2003; Nelson 2005; Balasse and Tresset 2007; Britton et al. 2009; Henton et al. 2010). This approach is undoubtedly of great interest for archaeologists, offering new insights into seasonal availability of animal resources, herd management and seasonality of site occupation in past societies (Balasse et al. 2003).

Nevertheless, potential difficulties have emerged, which need to be addressed before the method can be more widely applied to archaeological assemblages. First, the assessment of seasonality of birth is done through the assessment of inter-individual variability in the time sequence-the sequence of the seasonal cycle-recorded in a given tooth. Practically, seasonality of birth is assessed from $\delta^{18} \mathrm{O}$ sequential series by the identification of the position in tooth crown where the highest and/or lowest $\delta^{18} \mathrm{O}$ values of the cycle are measured, allowing comparison between individuals. However, this variability, measured as a distance on the tooth crown, may also be influenced by variability in the timing of tooth development, which affects which part of the tooth is being formed at a given age and leads to variability in tooth full size, to which the position in the tooth crown where the diagnostic $\delta^{18} \mathrm{O}$ values are measured should be related. How much of the observed inter-variability can be attributed to such developmental and morphological factors, and when those factors become more significant than differences due to birth seasonality, have not been assessed. This aspect must be investigated in a reference population of animals born within a short time period and submitted to similar external conditions.

Second, there is a strong temptation to use intra-tooth sequential analysis of enamel $\delta^{18} \mathrm{O}$ to determine the season of birth from the timing of tooth growth (Henton et al. 2010). However, the timing of tooth growth, which is known precisely for only very few species, might not be the timing of tooth mineralization, due to the delay in the process of enamel maturation. How this might affect the timing of the record of the isotopic signal has been shown in cattle (Balasse 2002), horse (Hoppe et al., 2004) and sheep tooth enamel (Zazzo et al. 2010). Alternatively, the birth season may be determined by comparison with reference data sets obtained on animals whose season of birth is known.

Such reference data sets are species and tooth dependent. For sheep, one reference set is published for the record of spring birth in the sheep third lower molar. It was acquired on primitive sheep from North Ronaldsay island (Orkney), presumably born during the population birth peak in April/May (Balasse et al. 2005; Balasse and Tresset 2007). In the present study, series of $\delta^{18} \mathrm{O}$ values were measured in the lower second molars of 10 sheep born within a few weeks of each other and submitted to the same environmental conditions until they were slaughtered on the same day, 18 months later. The objectives are: (1) to acquire a set of $\delta^{18} \mathrm{O}$ sequential data for spring birth, in the lower second molar of sheep; and (2) to measure inter-individual variability for a sheep population with a very narrow birth period. A model is proposed to quantify this variability while eliminating the influence of tooth size. 


\section{MATERIAL}

The study included 10 sheep raised on the island of Rousay in the Orkney archipelago. The region is under a temperate climate, heavily influenced by the Gulf Stream, with an annual amplitude of variation in temperature of around $9^{\circ} \mathrm{C}$. The highest ambient temperatures are usually reached in July and August and the lowest in February (Vose et al. 1992). The studied animals were derived from a working farm rather than an experimental farm, and as such more closely mirror the environmental conditions that might have been encountered in traditional herding systems in the past. The sheep are a Shetland cross. They were born around the end of April or the beginning of May 2003, within 4-6 weeks of each other, and were raised in the same cohort. They were slaughtered on 7 October 2004. The mandibles were collected just after slaughter and each sheep provided one lower second molar for the present study. The group included castrated rams and ewes; however, the mandibles were not identified by individual. The sheep grazed on terrestrial pasture. The farm water was supplied from natural and drilled wells, and the sheep also had access to streams running through the island. However, they were rarely seen drinking from these sources: most of their water came from vegetation, including plant water and meteoric water that was ingested with the grass. Six of these sheep (ROU 01, ROU 04, ROU 09, ROU 11, ROU 16 and ROU 17) were included in a previous study, where their enamel stable carbon isotope compositions were used as terrestrial references for comparison with seaweed-eating sheep (Balasse et al. 2009). For the present study, we completed the sequences previously sampled on these six sheep (see the 'Methods' section), and we added four individuals (ROU 6, ROU 07, ROU 08 and ROU 18).

\section{METHODS}

Enamel sampling was performed on the buccal side of the anterior lobe of the lower second molar. The tooth enamel surfaces were cleaned by abrasion with a tungsten drill bit. Enamel was sequentially sampled from a few millimetres away from the apex to the cervix of the crown, using a diamond burr bit. Each sample was a groove perpendicular to the tooth growth axis, drilled through the whole thickness of the enamel layer. The sampling spanned the whole crown height, including the lowest part bearing softer enamel due to incomplete mineralization (Fig. 1). In the six sheep included in a previous study (ROU 01, ROU 04, ROU 09, ROU 11, ROU 16 and ROU 17), the sampling was initially stopped before reaching softer enamel (Balasse et al. 2009). Because this part of the tooth, formed at the very end of the first year, represents an important milestone in the timing of tooth growth, the sampling was completed on these teeth until as close as possible to the enamel/root junction (except for ROU 01, whose tooth had served for other scientific purposes since the first sampling). The distance of each sample from the enamel/root junction from the furthest sample margin is recorded (Fig. 1). From 20 to 31 enamel samples were drilled out of each tooth, depending on the crown length, giving a total of 272 samples.

The enamel powder was pre-treated for bioapatite extraction as described in Balasse et al. (2002). The enamel was treated for $24 \mathrm{~h}$ with sodium hypochlorite $2-3 \%$ ( $0.1 \mathrm{ml}$ solution per $\mathrm{mg}$ of sample) to remove organic matter and then for $4 \mathrm{~h}$ in $0.1 \mathrm{M}$ acetic acid $\left(0.1 \mathrm{ml} \mathrm{mg}^{-1}\right)$ to remove exogenous carbonate. This protocol was designed to purify archaeological bioapatite. No exogenous carbonate is supposed to be present in modern enamel samples. However, because the first six sheep from a previous study (Balasse et al. 2009) were pre-treated for their isotopic values to be directly compared to those from archaeological samples, and because the pre-treatment is known to induce changes in the $\delta^{18} \mathrm{O}$ values of enamel (Koch et al. 1997), all samples had to be 


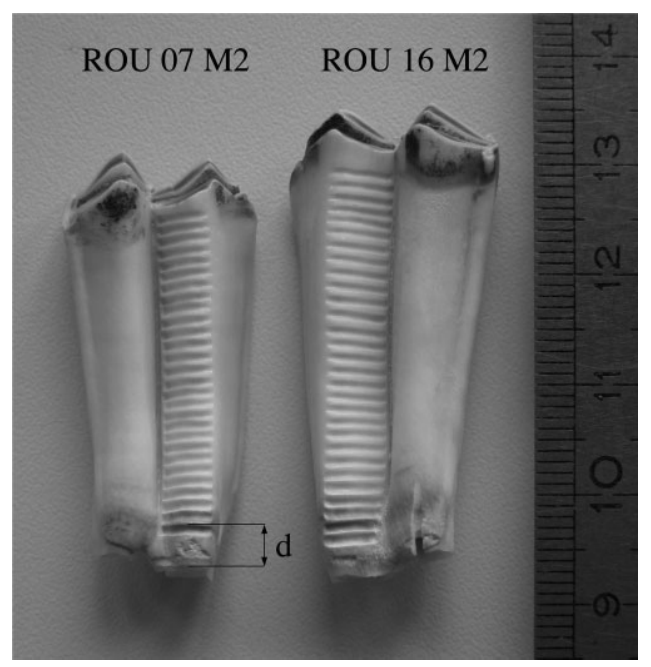

Figure 1 The sampled sheep teeth from Rousay (scale in $\mathrm{mm}$ ): $d$ is the distance of the sample from the enamel/root junction.

pre-treated. For three individuals (ROU 07, ROU 08 and ROU 18), the enamel samples were analysed before and after pre-treatment to determine whether the results from Koch et al. (1997), obtained on a small number of modern enamel samples, could be confirmed.

Bioapatite samples weighing from 550 to $650 \mu \mathrm{g}$ were reacted for $240 \mathrm{~s}$ with $100 \%$ phosphoric acid at $70^{\circ} \mathrm{C}$ in individual vessels in an automated cryogenic distillation system (Kiel IV device), interfaced with a Delta V Advantage isotope ratio mass spectrometer. The accuracy of the data was checked through the analysis of our internal laboratory carbonate standard (Marbre LM), whose $\delta^{18} \mathrm{O}$ value, normalized to the international standard NBS 19 , is $-1.83 \%$. Over the period of analysis of the bioapatite samples, from November 2009 to January 2010, the analytical precision calculated from 127 analyses of Marbre LM was $0.06 \%$ for $\delta^{18} \mathrm{O}$. Over the period of analysis of the six previous sheep, from March to May 2007, the analytical precision for $\delta^{18} \mathrm{O}$ was $0.04 \%$, from 51 analyses of Marbre LM. The correction applied to the enamel samples, from the measured value of Marbre LM, varied from $-0.26 \%$ o to $+0.01 \%$.

\section{RESULTS}

The mean percentage of weight loss induced by the pre-treatment is $47 \pm 5 \%$. Results from $\delta^{18} \mathrm{O}$ analysis of untreated enamel bioapatite and comparison with the values measured in pre-treated corresponding samples are shown in Table 1 and Figure 2. The pattern of variation of $\delta^{18} \mathrm{O}$ values within a tooth is similar before and after pre-treatment: the minimum and maximum $\delta^{18} \mathrm{O}$ values are recorded in the same place in the tooth crown and the amplitude of variation within each tooth differs slightly (Table 1 ). The difference in $\delta^{18} \mathrm{O}$ values between untreated and pre-treated enamel $\left(\delta^{18} \mathrm{O}\right.$ pre-treated $-\delta^{18} \mathrm{O}$ untreated $)$ varies from $-0.3 \%$ o to $1.9 \%$ and the mean difference is $1.0 \pm$ $0.4 \% o(N=81)$. This is close to the $0.9 \%{ }^{18} \mathrm{O}$-enrichment reported in Koch et al. (1997), although with a different protocol in the latter study $(2 \% \mathrm{NaOCl}$ for 1 day, then $0.1 \mathrm{M}$ acetic acid for 3 days, $0.04 \mathrm{ml}$ solution per $\mathrm{mg}$ of sample). This offset is lower in the last $10 \mathrm{~mm}$ of tooth crown towards the enamel/root junction (Fig. 2). 
Table 1 Minimum, maximum and mean differences in the stable oxygen isotope ratios $\left(\delta^{18} O\right)$ of untreated (utr) and pre-treated (ptr) enamel carbonate samples from three specimens, and the amplitude of variation of enamel carbonate $\delta^{18} \mathrm{O}$ within each tooth

\begin{tabular}{|c|c|c|c|c|c|c|}
\hline \multirow[t]{2}{*}{ Specimen } & \multirow[t]{2}{*}{$N$} & \multicolumn{3}{|c|}{$\Delta \delta^{18} O(p r t-u t r)$} & \multicolumn{2}{|c|}{ Amplitude of variation } \\
\hline & & Min. (\%o) & $\operatorname{Max} .(\% o)$ & Mean $\pm 1 \sigma(\% o)$ & utr $(\% \circ)$ & $\operatorname{ptr}(\% o)$ \\
\hline ROU 07 M2 & 24 & 0.6 & 1.4 & $1.1 \pm 0.2$ & 2.4 & 2.9 \\
\hline ROU 08 M2 & 27 & -0.2 & 1.1 & $0.7 \pm 0.3$ & 2.5 & 2.7 \\
\hline ROU 18 M2 & 30 & -0.3 & 1.9 & $1.2 \pm 0.5$ & 3.2 & 2.7 \\
\hline
\end{tabular}

Results from the $\delta^{18} \mathrm{O}$ analysis of pre-treated enamel are shown in Table 2 and Figure 3. All $\delta^{18} \mathrm{O}$ values are expressed versus VPDB. Overall, the $\delta^{18} \mathrm{O}$ values vary from $-6.5 \%$ to $-1.7 \%$. Within a tooth, the minimum $\delta^{18} \mathrm{O}$ values vary between $-6.5 \%$ and $-4.6 \%$ and the maximum $\delta^{18} \mathrm{O}$ values range between $-2.8 \%$ and $-1.7 \%$. The amplitude of variation within each second molar is between $2.7 \%$ and $4.0 \%$ (Table 2). From the lowest and highest $\delta^{18} \mathrm{O}$ values and from intra-tooth amplitude of variation, no individual diverges significantly from the remaining individuals (Student's $t$-test, 95\% confidence interval).

In all sheep, the pattern of variation of $\delta^{18} \mathrm{O}$ is sinusoidal, most probably reflecting the seasonal cycle. In the teeth where the sampling started very close to the lobe apex (ROU 6 M2 and ROU 18 M2, Fig. 3), the recorded sequence spans approximately a year. In other teeth, when the sampling started a few millimetres away from the apex (Figs 1 and 3) the sequence is less than a year, due to truncation of this part of the signal. The lowest $\delta^{18} \mathrm{O}$ values, reflecting the coldest months, were tracked at a distance from the enamel/root junction varying between $22.1 \mathrm{~mm}$ and $33.1 \mathrm{~mm}$ (Table 2). Given that the sheep were born in the spring, these correspond to their first winter. The highest $\delta^{18} \mathrm{O}$ values, reflecting the warmest months, were tracked at a distance from the enamel/root junction varying between $5.1 \mathrm{~mm}$ and $13.7 \mathrm{~mm}$ (Table 2). These values correspond to the second summer of the sheep's life.

\section{DISCUSSION}

\section{Difference in the pre-treatment induced offset between mature and immature enamel}

In ROU 08 M2 and ROU 18 M2, a difference was observed in the pre-treatment effect in the last $10 \mathrm{~mm}$ of tooth crown. In this part of the tooth, enamel was not fully mineralized, as witnessed from visual observation (Fig. 1) and during the sampling process from a lower resistance of the enamel to the drill. This was confirmed by a lower extraction yield after pre-treatment (data not shown) due to a higher initial organic content. An explanation for such a difference in the pre-treatment-induced isotopic offset between mature and immature enamel may be proposed, although this observation, made on a very limited number of samples, needs to be confirmed. As a possible and non-exclusive explanation for the trend induced by pre-treatment, Koch et al. (1997) suggested that partial dissolution by acetic solution might change the relative proportion of carbonate in phosphate $\left(\mathrm{PO}_{4}{ }^{3-}\right)$ and hydroxyl $\left(\mathrm{OH}^{-}\right)$lattice sites of bioapatite by, for example, removing preferentially the more weakly bonded sites. This mechanism also predicts a direct link between the isotope value of bioapatite and lattice site occupancy, which has not been tested 


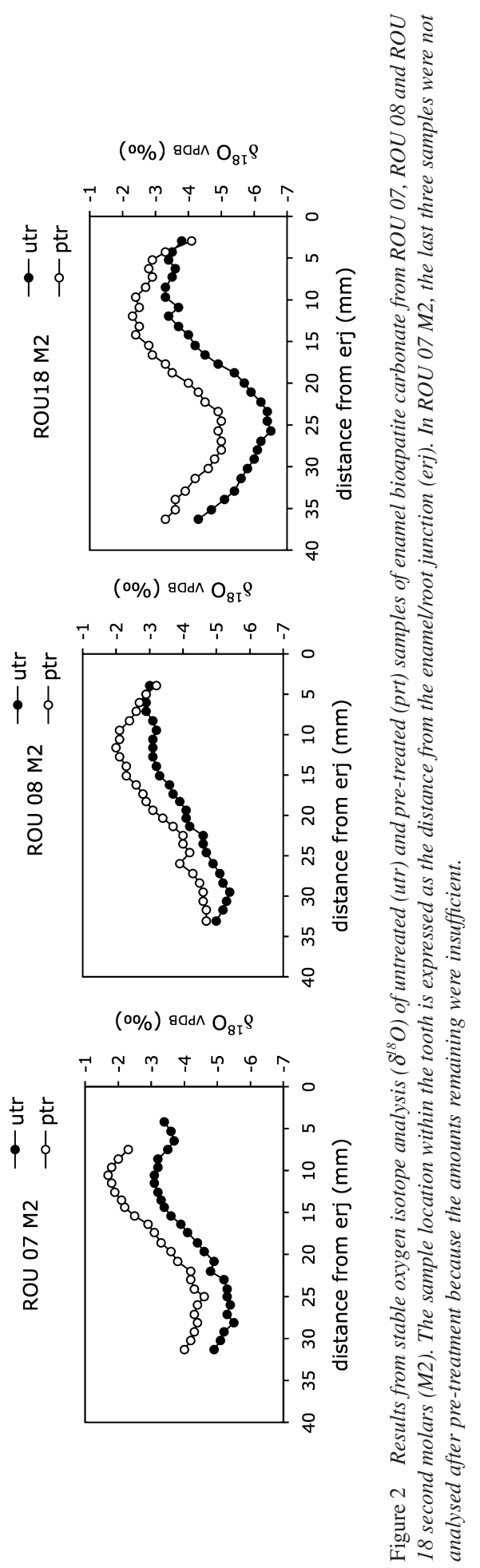




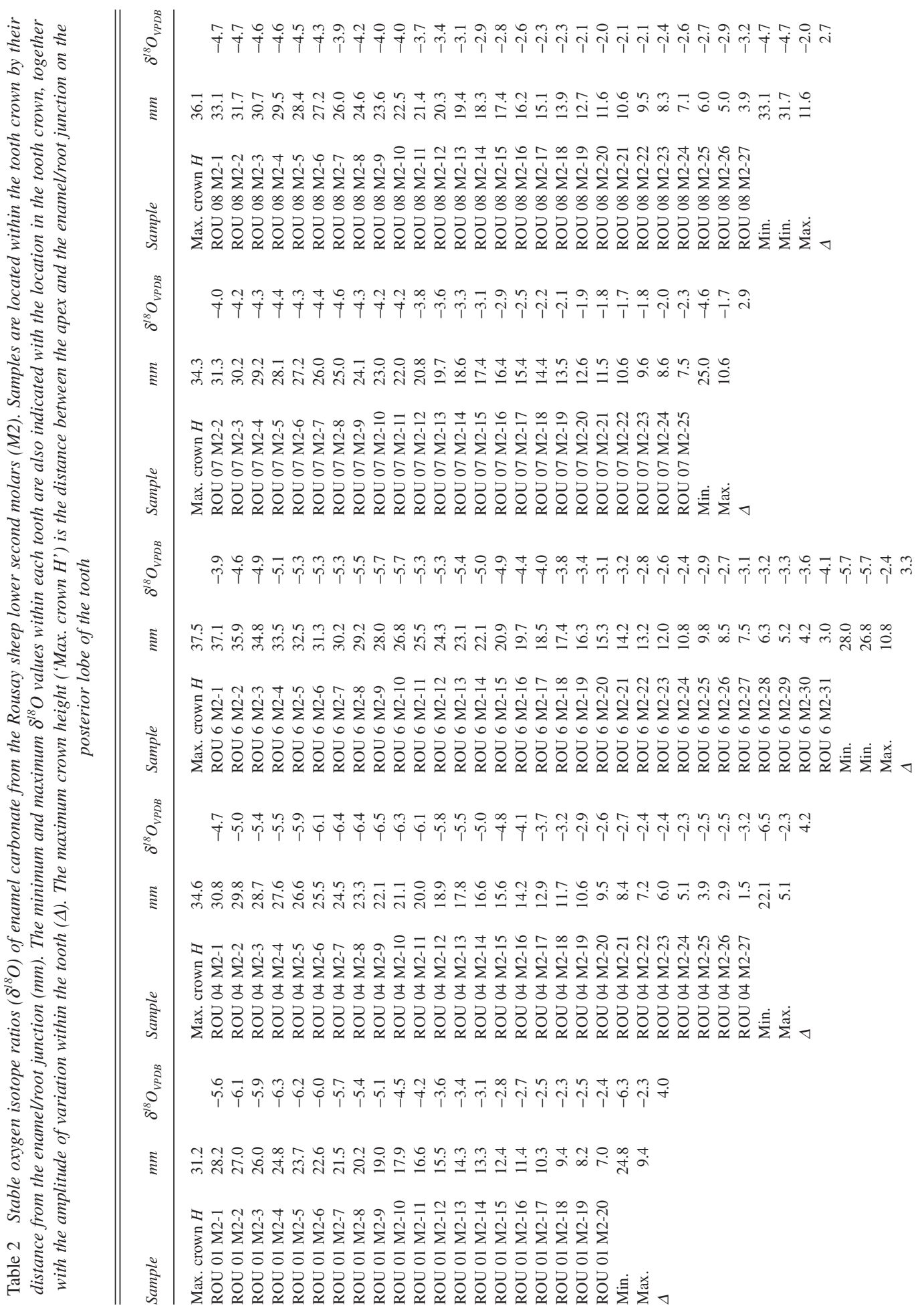




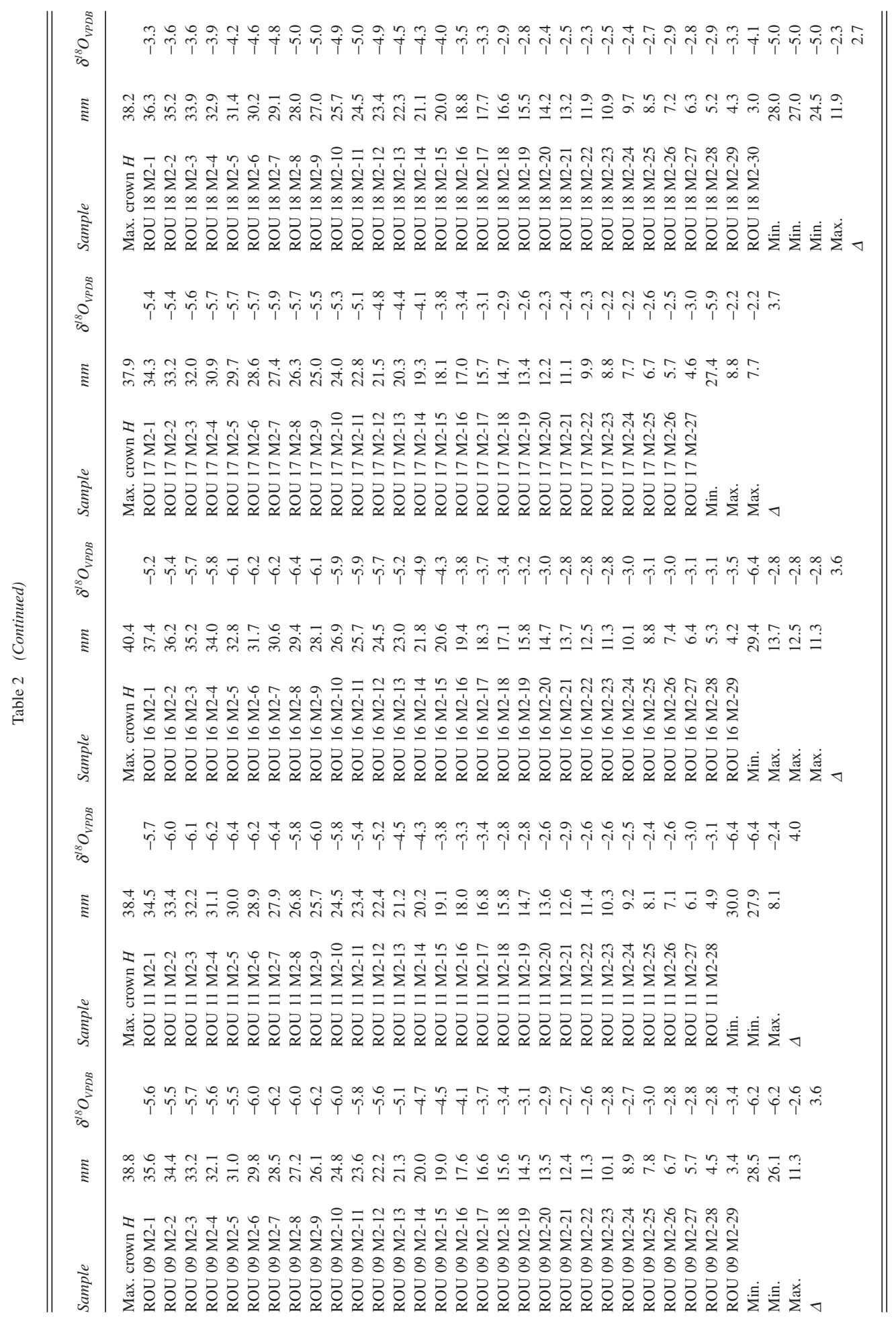



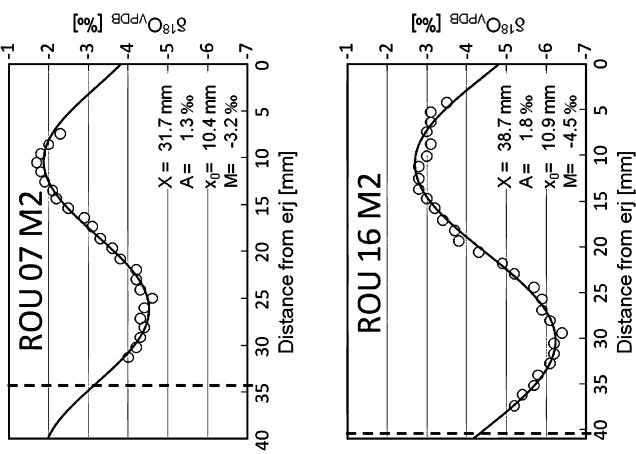

$[0 \%]$

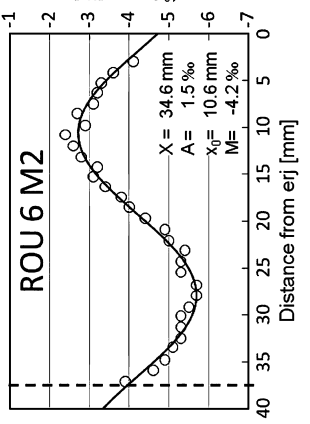

[\%\%] ${ }^{\text {gad }} \mathrm{O}_{81} \mathrm{~S}$
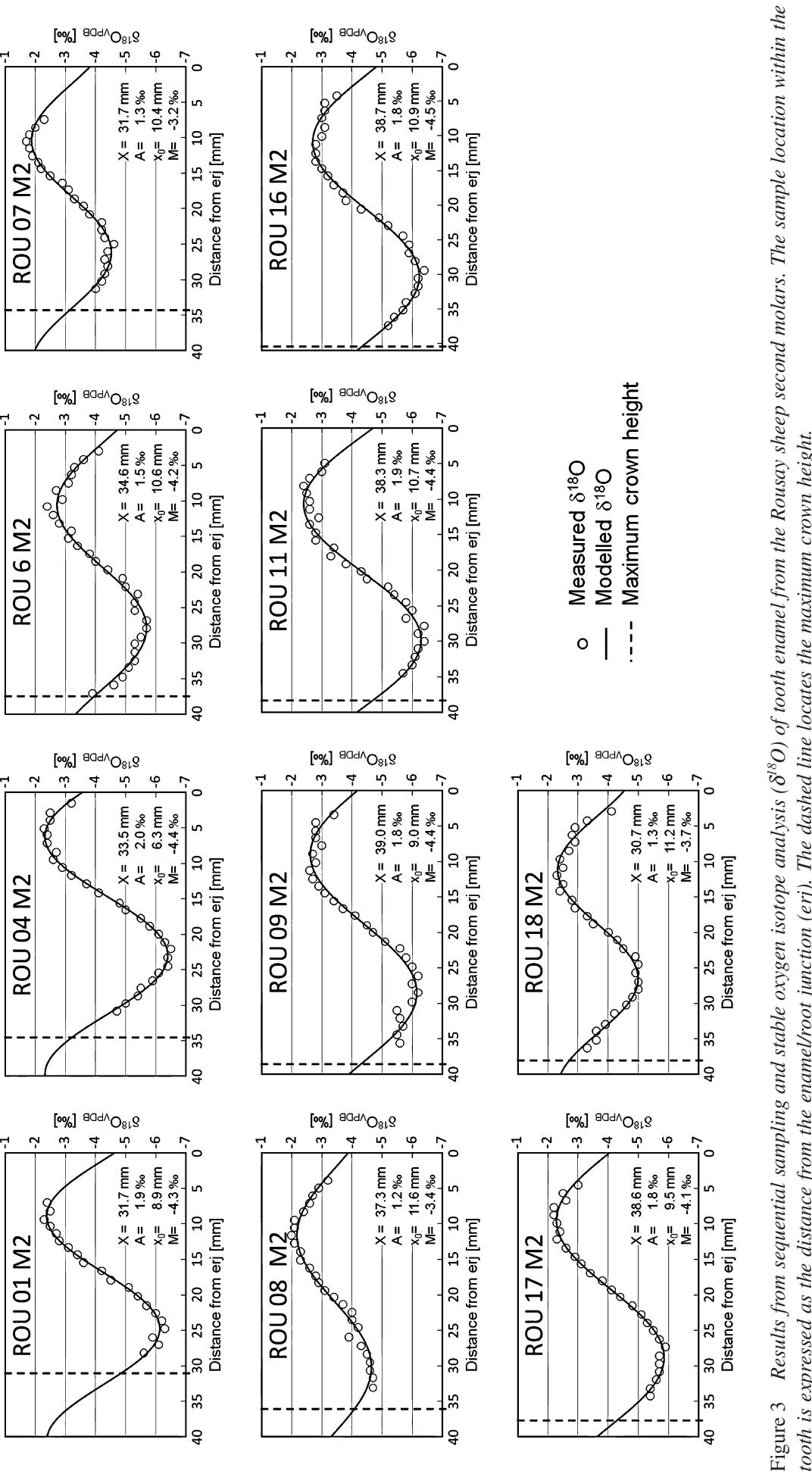

[0\%] ${ }^{80 \mathrm{dA}} \mathrm{O}_{81} \mathrm{~s}$

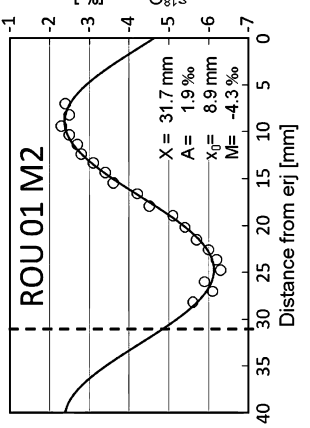

$[0 \%]^{\mathrm{gadn}} \mathrm{O}_{81} \mathrm{~S}$

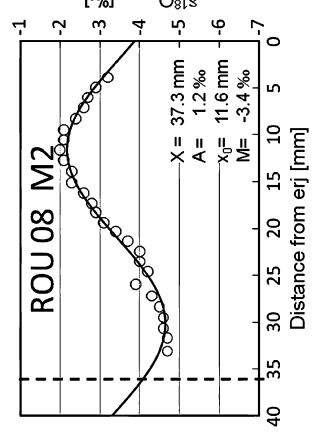

[0\%] ${ }^{\mathrm{gadA}} \mathrm{O}_{81} \mathrm{~S}$

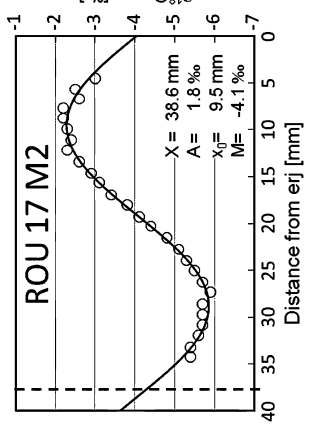

$\stackrel{2}{\stackrel{2}{2}} \underset{\infty}{\infty}$

这

密:

ก

के

苛

ก.

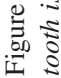


since. If this explanation is correct, the pre-treatment offset might also differ with a change in the relative proportion of adsorbed/structural carbonate and/or carbonate present at the $\mathrm{PO}_{4}{ }^{3-} / \mathrm{OH}^{-}$ lattice site. Aoba and Moreno (1990) have shown that during enamel development, incorporation of carbonate into bioapatite crystals changes quantitatively and qualitatively. A significant amount of carbonate incorporated during the secretory phase is labile, adsorbed on the crystal surface. During maturation, the labile component decreases and most of the carbonate ions are incorporated into the crystal lattice. As for the sites occupied by carbonate ions in the crystal lattice, enamel crystals at early stages of mineralization include mainly carbonate substituted at the $\mathrm{PO}_{4}{ }^{3-}$ site, while maturation sees a decrease in the number of carbonate ions substituted per atom mass of calcium and a concomitant increase in carbonate ions substituted at the $\mathrm{OH}^{-}$sites (Aoba and Moreno 1990; Aoba 1996). Therefore, the isotopic shift induced by the pre-treatment may differ between mature enamel and enamel in earlier mineralization stages, although the exact mechanisms leading to a very low shift of the isotopic signal in immature enamel, in this study case, are unexplained. Alternatively, the measurement of the $\delta^{18} \mathrm{O}$ values on untreated immature enamel might have been affected by a higher organic content in these samples.

\section{Inter-individual variability in the $\delta^{18} O$ values}

Within the studied population, inter-individual variability is $1.1 \%$ o for the maximum $\delta^{18} \mathrm{O}$ values and reaches $1.9 \%$ o for the minimum $\delta^{18} \mathrm{O}$ values recorded in the second molar. The analytical procedure-including the precision in the volume of enamel sampled (corresponding to a certain amount of time, over which the isotopic signal is averaged), the differential effect of pretreatment and the analytical precision-explains only a very small part of this variability. The rest must be explained by inter-individual variability in physiology (from body water balance to the process of enamel mineralization) and possible differences in the input signal, although those would be minor-including, for instance, different relative proportions of plant water and drinking water. The experimental protocol designed for this study does not compare with carefully controlled conditions as far as environmental factors are concerned. However, the sheep included in this study were submitted throughout their lives to environmental conditions that were as similar as they could ever be, within the constraints of a real herding system: born on the same farm, they moved in a cohort with each other over a very small territorial range, until they were slaughtered on the same day.

\section{Sequence of the seasonal cycle recorded in M2 and duration of enamel mineralization}

In sheep, the second molar starts to form during the second month of life and its crown is completed by the time the sheep has reached the age of 12 months (Weinreb and Sharav 1964, Awassi breed; Milhaud and Nézit 1991, south Pre-Alps breed; Zazzo et al. 2010, Suffolk cross). No information on the timing of tooth growth in the Shetland breed has been found. Given the consistency of previous observations on different breeds of sheep, it is assumed that the timing of tooth growth in Shetland sheep is close to that of previously cited breeds.

According to this timing of tooth development, in sheep born around the end of April or the beginning of May, the earliest part of the M2 crown would be expected to form at the end of May or the beginning of June, when they were 1 month old, and the final part of the M2 crown at the end of April or the beginning of May of the following year, when they were 1 year old. Unfortunately, the $\delta^{18} \mathrm{O}$ of the ingested water-or, more generally, the environmental water-was not controlled over the sheep's lifetime. Precipitation $\delta^{18} \mathrm{O}$ is closely related to surface air 

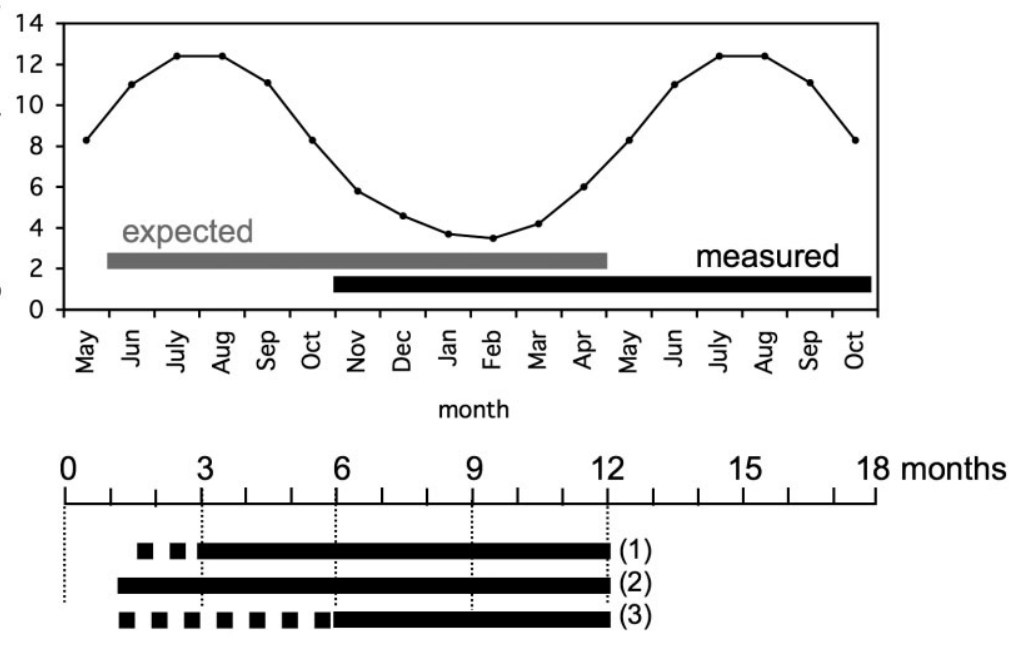

Timing of second molar growth in (1) Awassi sheep (Weinreb and Sharav 1964)

(2) South Pre-Alps (Milhaud and Nézit 1991)

(3) Suffolk cross (Zazzo et al. 2010)

Figure 4 The average ambient temperature in the South Orkney islands (Vose et al. 1992) and the expected sequence of the seasonal cycle recorded in the sheep second molar, from the timing of tooth growth. The sequence measured in the sheep second molar is shifted.

temperature at high and middle latitudes (Gat 1980; Rozanski et al. 1993), and consequently the pattern of monthly variations in precipitation $\delta^{18} \mathrm{O}$ may be close to the pattern of monthly variation of ambient temperature in its trends. The expected sequence of the seasonal cycle, estimated from monthly variation of the ambient temperature, is reported in Figure 4. Average temperature data from Vose et al. (1992) were obtained over 959 months between 1827 and 1906, averaging years of data. They may not be the most appropriate data to compare to the isotopic data acquired in a specific year. However, in the absence of direct control of precipitation $\delta^{18} \mathrm{O}$ over the time of formation of the teeth included in this study, they were the unique data set that could be referred to for this purpose.

The measured pattern of $\delta^{18} \mathrm{O}$ variation within sheep enamel differs from our expectations (Fig. 4). Although enamel was sampled on the posterior lobe, where tooth wear was very light and the crown height was still intact, the sampling was started a few millimetres lower to avoid reduction of sample size due to the narrowing of the tooth crown towards the apex. The maximum crown heights range between $31.2 \mathrm{~mm}$ and $40.4 \mathrm{~mm}$ (Table 2). They have been reported on the graphs in order to estimate what part of the signal was truncated by the sampling in each tooth (Fig. 3). The isotopic signal is missing over 2-3 mm on most teeth, except in ROU $6 \mathrm{M} 2$, where the sampling was started at the very beginning of the crown. In this specimen, the earliest isotopic signal is close to the mean between the maximum and minimum $\delta^{18} \mathrm{O}$ values recorded over the year. According to the pattern of annual variations in surface air temperature (Vose et al. 1992), this could be reached at the end of October (Fig. 4). Compared to the expected date of the end of May/beginning of June, this suggests a 5 month shift in the reading of the seasonal cycle recorded in the tooth enamel. 
Because of the reduction of the enamel layer thickness towards the cervical margin of the crown, the sampling could be performed as far as the enamel/root junction only in one specimen (ROU 04). From this specimen and from others where only a couple of millimetres are missing, the $\delta^{18} \mathrm{O}$ values measured at the very end of the crown would correspond to early autumn (ROU 04) to autumn (ROU 18), roughly from late September to late October. Compared to the expected April date, this indicates a 5-6 month shift in the record of the seasonal cycle in the tooth enamel. In a controlled study of Suffolk sheep, Zazzo et al. (2010) estimated the duration of enamel maturation time to be 4 months in the second molar. From measurements on thin sections of developing enamel, Suga (1982) estimated that two thirds of enamel developmental time is devoted to maturation in sheep molars. A 4 month maturation would therefore correspond to 6 months for the whole developmental process. It is therefore apparent that Zazzo et al.'s study and the present work lead to similar conclusions. This important delay in enamel maturation highlights the fact that the season of birth cannot be deduced directly from the timing of tooth growth in sheep.

\section{Location in crown height of maximum and minimum $\delta^{18} O$ values}

In archaeological assemblages, the season and seasonality of birth are assessed from $\delta^{18} \mathrm{O}$ sequential series by the identification of the position in the tooth crown at which the highest and/or lowest $\delta^{18} \mathrm{O}$ values of the cycle are measured. This allows comparison between individuals. In our data set, the lowest $\delta^{18} \mathrm{O}$ values were measured at a distance from the enamel/root junction varying from 33.1 to $22.1 \mathrm{~mm}$ and the highest $\delta^{18} \mathrm{O}$ values at a distance varying from 13.7 to $5.1 \mathrm{~mm}$ (Table 2 and Fig. 3). This distance is directly linked to the age of the individual when this part of the tooth is forming, but it is also linked to tooth size. However, within the sampled population, the full crown height of the second molar ranges between $31.2 \mathrm{~mm}$ and $40.4 \mathrm{~mm}$, showing that tooth size varies greatly (see also Fig. 1). Direct comparison between individuals could be acceptable after normalizing the distance from the enamel/root junction to each individual's full crown height. However, the full crown height is attained-and measurable - only over a very short time in sheep molars, because the crown comes into wear at about the same time as it reaches its full length. For this reason, such normalization is difficult to envisage in archaeological assemblages, where the number of specimens of sheep second molars showing full crown height (roughly between 12 and 18 months old) might not be high enough for a study of birth seasonality/season, depending on the exploitation strategy and therefore the structure of the herd mortality profile.

Another way to eliminate inter-individual variability in tooth size is to normalize the data to the periodic cycle identified from the $\delta^{18} \mathrm{O}$ values, which should represent a whole-year record in each individual, whatever the tooth size and growth rate. This can be done using the model described below.

\section{Description of the model}

The sequence of $\delta^{18} \mathrm{O}$ values measured in the sheep teeth can be modelled using a function mainly based on a cosine, as follows:

$$
\delta^{18} \mathrm{O}_{\mathrm{m}}=A \mathrm{e}^{\left(\frac{x-x_{B}}{x_{A}}\right)} \cos \left(2 \pi \frac{x-x_{0}}{X+b x}\right)+M+p x
$$


where the variables are defined as follows. $\delta^{18} \mathrm{O}_{\mathrm{m}}$ is the modelled $\delta^{18} \mathrm{O} ; x$ is the distance from the enamel/root junction; $X$ is the period (in $\mathrm{mm}$ ), corresponding to the length of tooth crown potentially formed over a whole annual cycle. $A$ is the amplitude $[=(\max .-\min ) / 2].($ in $\% o)$ and depends on the amplitude of the isotopic signal; $x_{0}$ is the delay $(\mathrm{mm})$, which depends on the time of the year when tooth growth started $-\delta^{18} \mathrm{O}$ attains its maximum value when $x=x_{0}$. $M$ is the mean $[=(\max .+\min ) / 2$.$] expressed in \% o . p$ is the slope $\left(\right.$ in $\left.\% o \mathrm{~mm}^{-1}\right)$ of the mean-when the sequence measured spans over a year, the mean $M$ might change from a year to another (change in the mean annual ambient temperature, for example). $x_{\mathrm{A}}$ and $x_{\mathrm{B}}$ (in $\mathrm{mm}$ ) model the attenuation of the amplitude $A ; x_{\mathrm{A}}$ is the severity of the attenuation, according to an exponential function whose lateral shift is described by $x_{\mathrm{B}}$. Such parameters will be important, for example, if tooth growth rate slows down towards the tooth neck. $b$ is the gradation of the period (no unit), also related to possible changes in tooth growth rate from the apex towards the neck of the crown. The function is close to that proposed by Bernard et al. (2009), with the addition of the last four parameters $\left(p, x_{\mathrm{A}}, x_{\mathrm{B}}\right.$ and $\left.b\right)$. Figure 5 highlights how the variation of each parameter might influence the model.

\section{Application of the model to the data set}

The best fit of the different parameters of the model to the measured data was determined using an iterative method, and a minimization of the sum of the square of the difference between the model and the measurements (the method of least squares). For this study, the calculations have been carried out using Microsoft Excel software, but any data analysis program can be used. First, the model was applied with $p, b$ and $x_{\mathrm{B}}$ fixed to 0 and $x_{\mathrm{A}}$ fixed to $10^{6}$, with only $X, A, x_{0}$ and $M$ allowed to vary: this will be referred to hereafter as the four-parameter model. The results from the calculation of the best fit for combined variation of $X, A, x_{0}$ and $M$ are reported in Table 3 . Among 10 specimens, the period $X$, corresponding to the length of tooth crown mineralized over a year, varies from 30.7 to $39.0 \mathrm{~mm}$ (mean $=35.8 \mathrm{~mm}$ ). The distance from the enamel $/$ root junction where the highest $\delta^{18} \mathrm{O}$ values are recorded $\left(x_{\max }=x_{0}\right)$ varies between 6.3 and $11.6 \mathrm{~mm}$ $($ mean $=9.9 \mathrm{~mm})$. The lowest $\delta^{18} \mathrm{O}$ values $\left(x_{\min }=x_{0}+X / 2\right)$ were recorded at between 23.0 and $30.3 \mathrm{~mm}($ mean $=27.6 \mathrm{~mm})$ from the enamel/root junction (Table 3 and Fig. 6 (a)). These results are similar to, but probably more accurate than, the previous estimations from raw data (5.1$13.7 \mathrm{~mm}$ and $22.1-33.1 \mathrm{~mm}$ for the location of highest and lowest $\delta^{18} \mathrm{O}$ values, respectively), because analytical precision could arbitrarily create false maximum and minimum data points. In this population, the inter-individual variability in the position in the tooth crown of the highest and lowest $\delta^{18} \mathrm{O}$ values, resulting mainly from tooth size, is $5.3 \mathrm{~mm}$ and $7.3 \mathrm{~mm}$, respectively.

When adding parameter $b$ to the four-parameter model, $b$ was always very low (lying between -0.3 and 0.6 ), which suggests that only a very slight variation of tooth growth rate with time could be detected on this data set. Such variation is probably easier to quantify on sequential $\delta^{18} \mathrm{O}$ values spanning over one periodic cycle. Using this five-parameter model, the modelled $x$ values for maximum $\delta^{18} \mathrm{O}\left(x_{\max }=x_{0}\right)$ and minimum $\delta^{18} \mathrm{O}\left[x_{\min }=\left(X+2 x_{0}\right) /(2-b)\right]$ were almost identical to those obtained with the four-parameter model $\left(\Delta x_{\max } \leq 0.6 \mathrm{~mm} ; \Delta x_{\min } \leq 0.2 \mathrm{~mm}\right.$-except in ROU 08, where $\Delta x_{\min }=2.1 \mathrm{~mm}$ ).

When applying all eight parameters $\left(X, A, x_{0}, M, p, x_{\mathrm{A}}, x_{\mathrm{B}}\right.$ and $\left.b\right)$ to the data set, $x_{\mathrm{A}}$ always remained very high $\left(10^{6}\right)$ and $\mathrm{x}_{\mathrm{B}}$ very low $\left(10^{-7}\right.$ to $\left.10^{-5}\right)$. The very small influence of these parameters on the model suggests that no attenuation of the isotopic signal towards the neck of the tooth is detected on this data set. The slope $p$ varied between -0.1 and $0.3 \% \circ \mathrm{mm}^{-1}$. Such slopes were considered unsuitable to describe the data set. This parameter might be more adapted 
(a)
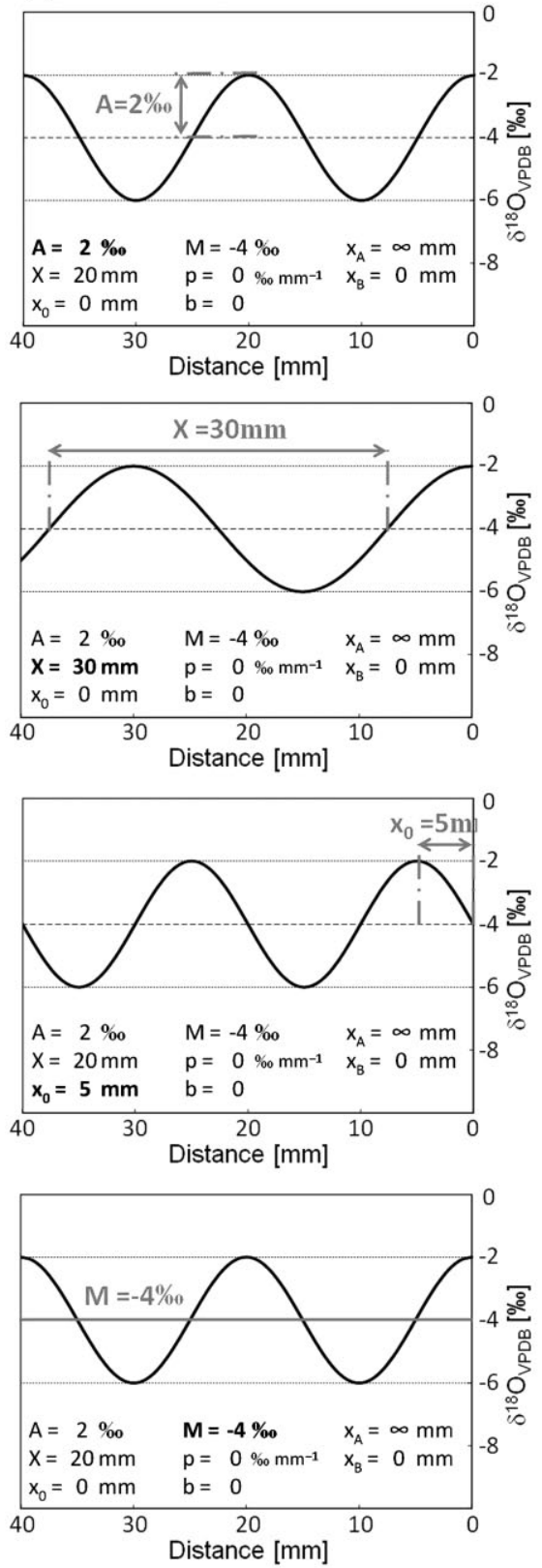
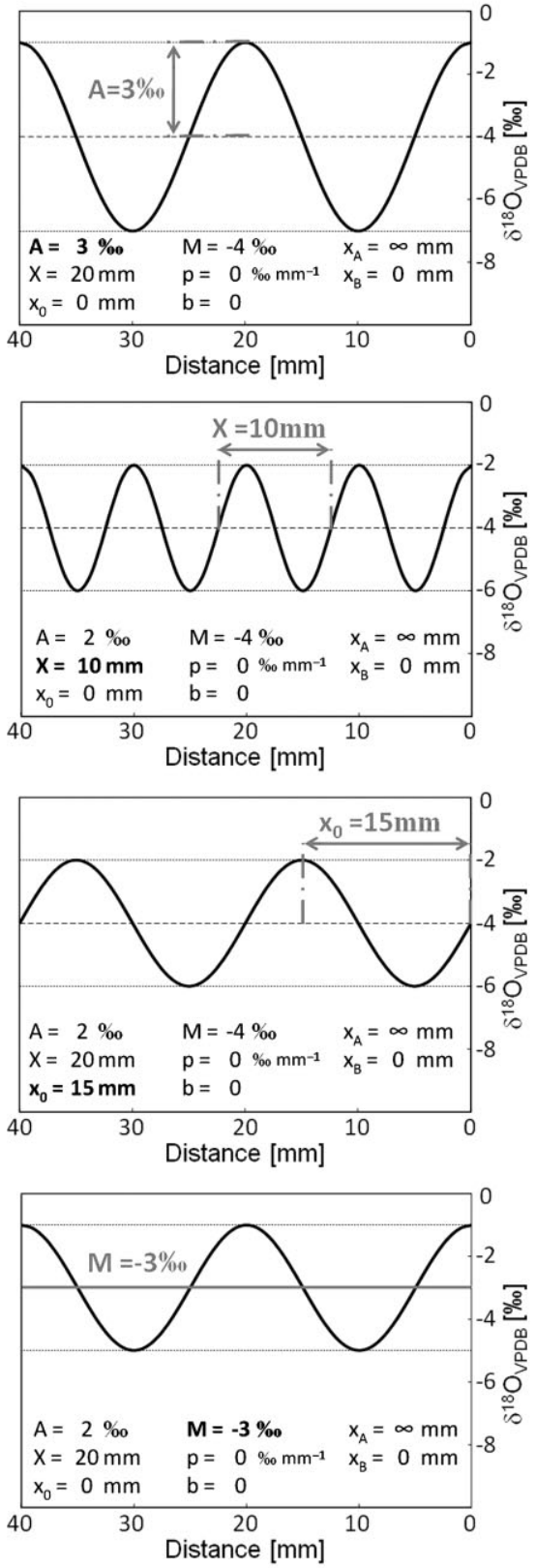

Figure 5 The definition of the eight parameters included in the model and the influence of each of them on the shape of the cosine function: (a) the parameters included in the four-parameter model; (b) additional parameters. 
(b)
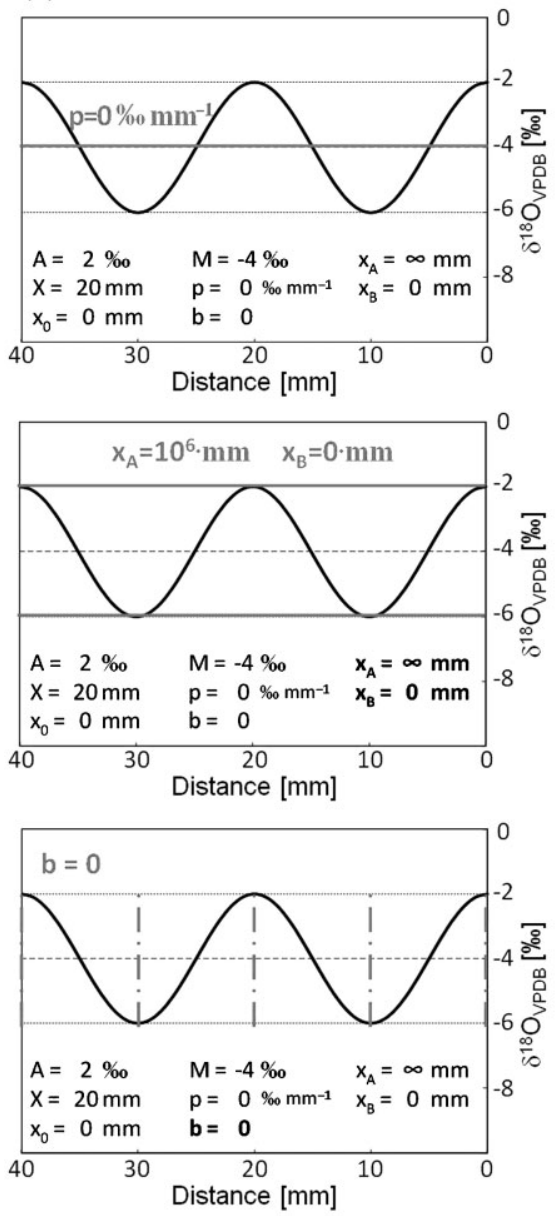
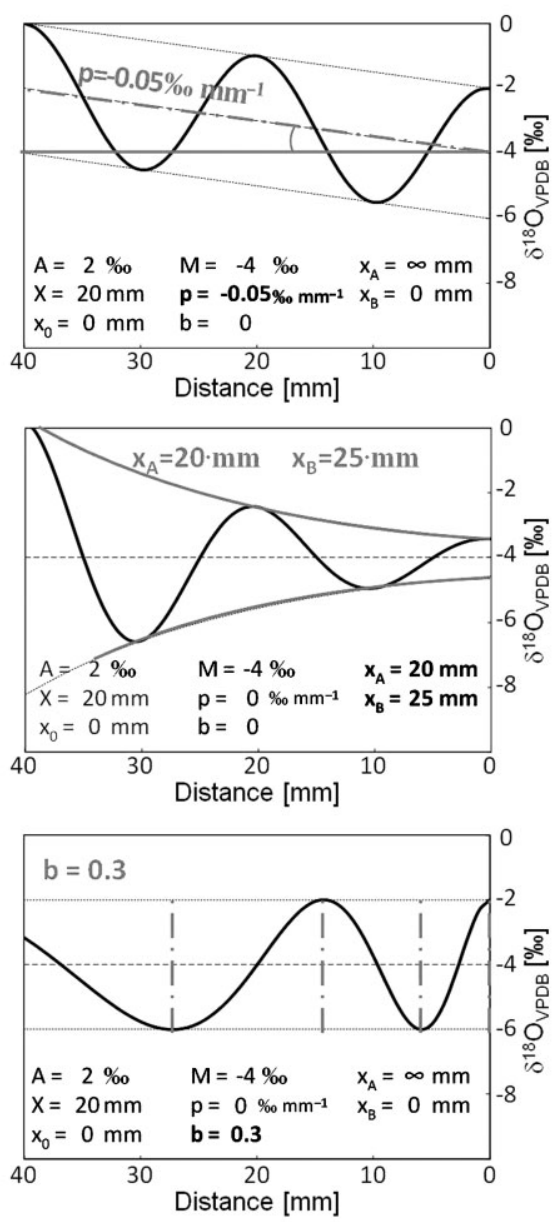

Figure 5 Continued.

to longer sequences, spanning over one periodic cycle. Using the eight-parameter model, calculation of $x_{\min }$ and $x_{\max }$ yielded different results from those obtained with the four-parameter model $\left(0.6 \leq \Delta x_{\max } \leq 3.7 \mathrm{~mm} ; 0 \leq \Delta x_{\min } \leq 8.7 \mathrm{~mm}\right)$.

Using the results from the four-parameter model, $x_{\min }$ and $x_{\max }$ for each individual were normalized to the respective period $X$. Values for $x_{\max } / X\left(=x_{0} / X\right)$ vary from 0.19 to 0.37 (mean $=$ $0.28 \pm 0.05$ ). Values for $x_{\min } / X$ vary from 0.69 to 0.87 (mean $=0.78 \pm 0.05$ ) (Table 3 and Fig. 6 (b)). From this, it may be concluded that when inter-individual variability due to tooth size is eliminated:

- All sheep gave very similar results. Eight are within the standard deviation around the mean; they must be considered indistinguishable. ROU 04 and ROU 18 deviate slightly from the mean, suggesting that tooth size alone cannot explain this difference. Nevertheless, both stay within an interval of plus or minus twice the standard deviation from the mean, which means that the data are coherent. Considering all eight remaining sheep, the inter-individual variability observed in 


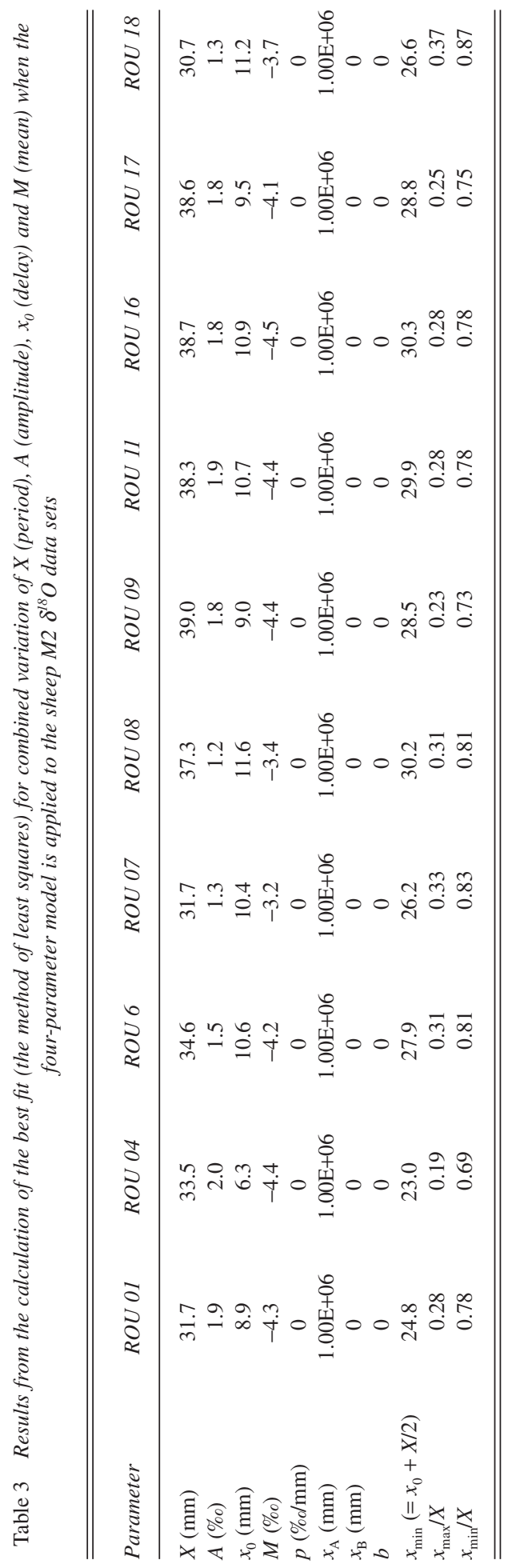


(a)
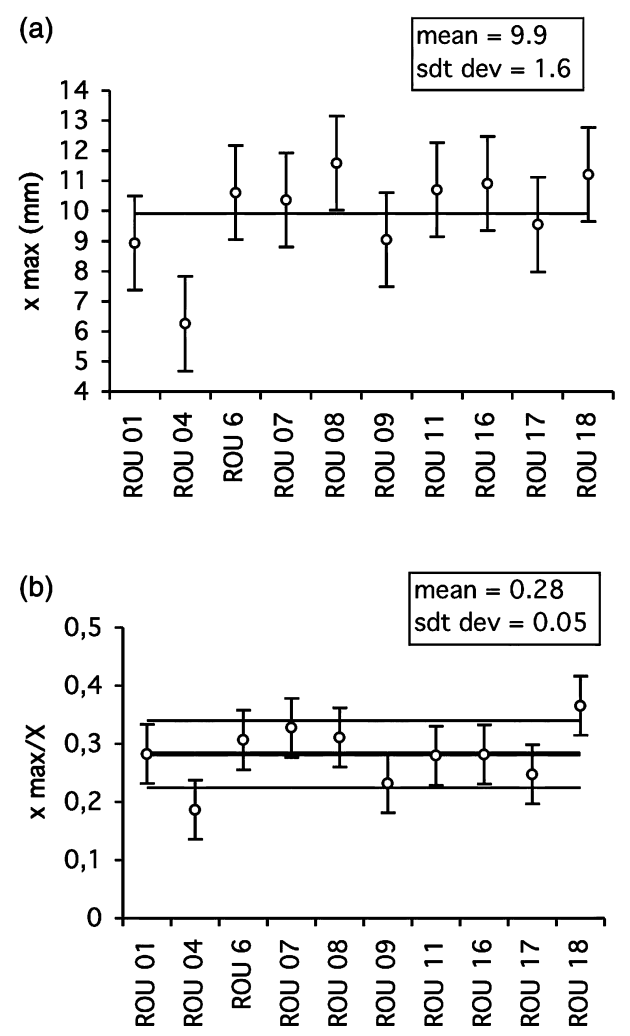
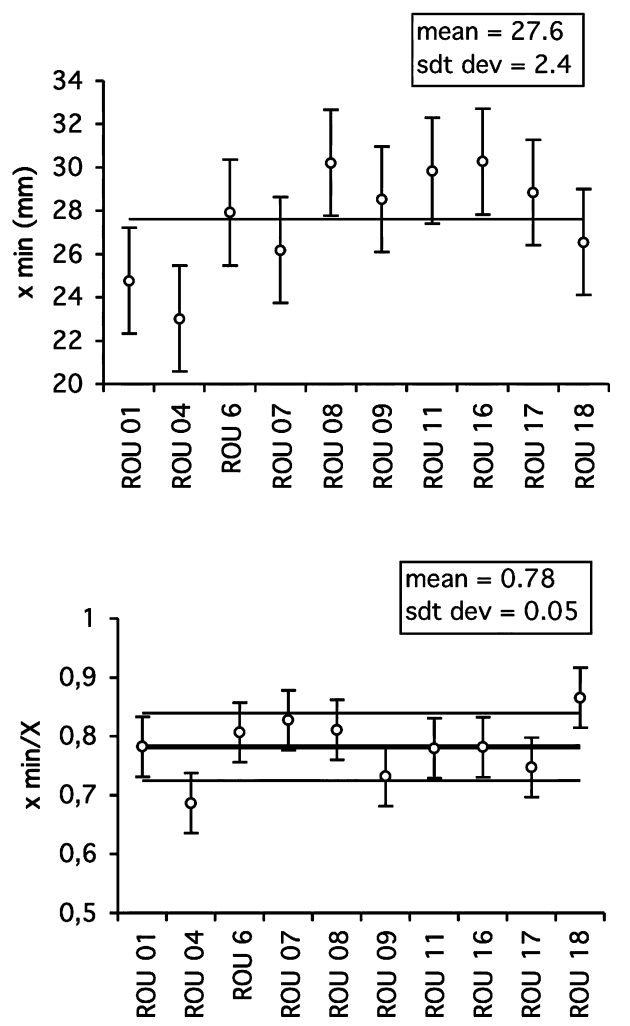

Figure 6 (a) The location in the tooth crown of the highest $\left(x_{\max }\right)$ and lowest $\left(x_{\min }\right)$ values in the 10 specimens. (b) The normalization of these distances to the period $X$.

the location of the highest $(2.7 \mathrm{~mm})$ and lowest $\delta^{18} \mathrm{O}$ values $(5.5 \mathrm{~mm})$ might be attributed to tooth size.

- The Rousay sheep were born over a maximum period of 6 weeks (or 0.11 year). The precision for the whole procedure described in this study (data acquisition, modelling and normalization to the periodic cycle) is lower than the dispersion of the births (Fig. 6 (b)), suggesting that the error in the attribution of a date of birth using this procedure is better than 6 weeks.

- The Rousay sheep have recorded the minimum and maximum $\delta^{18} \mathrm{O}$ values on average at $78 \%$ and $28 \%$ of the end of the recorded periodic cycle, respectively, the end being defined when $x=$ 0 (when the crown growth reaches the enamel/root junction). These may be considered as references for births occurring around the end of April or the beginning of May.

\section{CONCLUSIONS}

This data set offers a new reference for the record of April/May birth in the sheep lower second molar. The 5-6 month delay for completion of enamel mineralization reaffirms the usefulness of such reference data sets to determine the season of birth, which must not be estimated directly from the timing of tooth growth.

A model mainly based on a cosine function and involving eight parameters $(X=$ period, $A=$ amplitude, $x_{0}=$ delay, $M=$ mean, $p=$ slope of the mean, $x_{\mathrm{A}}$ and $\mathrm{x}_{\mathrm{B}}=$ attenuation of the amplitude, 
and $b=$ gradation of the period) was proposed to analyse the data. The last four parameters, $p, x_{\mathrm{A}}$, $x_{\mathrm{B}}$ and $b$, were not found to be very useful in describing the data set in this case: only a very slight variation of tooth growth rate with time and no attenuation of the isotopic signal towards the cervical margin of the crown could be detected on this data set. However, these parameters might be important to describe cyclic stable isotope variations in teeth whose growth spans several years.

The four-parameter (period, amplitude, delay and mean) model was found to be very useful to determine more accurately the period and the actual location in the tooth crown where the maximum and minimum $\delta^{18} \mathrm{O}$ values occur. The period was found to be $35.8 \mathrm{~mm}$ on average, suggesting that a minimum crown height of $17.9 \mathrm{~mm}(X / 2)$ might be required to record the position of both the maximum and minimum $\delta^{18} \mathrm{O}$ values over a natural annual seasonal cycle. Tooth remains with a lower crown height might not be well suited to the determination of seasonality and season of birth. On average, the maximum and minimum $\delta^{18} \mathrm{O}$ values occurred, respectively, at $9.9 \mathrm{~mm}$ and $27.6 \mathrm{~mm}$ from the tooth enamel/root junction. In this regard, maximum inter-individual variability due to tooth size was $5.5 \mathrm{~mm}$ in this population, suggesting that shifts over this distance in the record of the seasonal cycle must not be interpreted in terms of season of birth. On average, the Rousay sheep have recorded the minimum and maximum $\delta^{18} \mathrm{O}$ values at, respectively, $78 \%$ and $28 \%$ of the end of the recorded periodic cycle. These may be considered as references for births occurring around the end of April or the beginning of May.

\section{ACKNOWLEDGEMENTS}

This research was supported by a NERC programme, 'Refining palaeodietary methods of determining animal diets in antiquity: case study of seaweed as fodder in coastal environments' (NER/B/S/2003/00223, dir. I. Mainland, University of Bradford), the Programme 'Pluriformation PPF biomineralization of the MNHN' (dir. A. Meibom, MNHN), funded by the Ministère délégué à l'Enseignement supérieur et la Recherche, and an ERC Starting Grant 'SIANHE' (GA 202881 dir. M. Balasse, MNHN). We would like to thank Robert Mainland, who provided the sheep mandibles, and Karen Chapman, who prepared them for tooth extraction. We also thank two anonymous referees for their useful and benevolent comments.

\section{REFERENCES}

Aoba, T., 1996, Recent observations on enamel crystal formation during mammalian amelogenesis, The Anatomical Record, 245, 208-18.

Aoba, T., and Moreno, E. C., 1990, Changes in the nature and composition of enamel mineral during porcine amelogenesis, Calcified Tissue International, 47, 356-64.

Balasse, M., 2002, Reconstructing dietary and environmental history from enamel isotopic analysis: time resolution of intra-tooth sequential sampling, International Journal of Osteoarchaeology, 12, 155-65.

Balasse, M., and Tresset, A., 2007, Environmental constraints on reproductive activity of domestic sheep and cattle: what latitude for the herder? Anthropozoologica, 42(2), 71-88.

Balasse, M., Mainland, I., and Richards, M. P., 2009, Stable isotope evidence for seasonal consumption of seaweed by modern and archaeological sheep in the Orkney archipelago (Scotland), Environmental Archaeology, 14, 1-14.

Balasse, M., Ambrose, S. H., Smith, A. B., and Price, T. D., 2002, The seasonal mobility model for prehistoric herders in the south-western Cape of South Africa assessed by isotopic analysis of sheep tooth enamel, Journal of Archaeological Science, 29, 917-32.

Balasse, M., Smith, A. B., Ambrose, S. H., and Leigh, S. R., 2003, Determining sheep birth seasonality by analysis of tooth enamel oxygen isotope ratios: the Late Stone Age site of Kasteelberg (South Africa), Journal of Archaeological Science, 30, 205-15. 
Balasse, M., Tresset, A., Dobney, K., and Ambrose, S. H., 2005, The use of isotope ratios to test for seaweed eating in sheep, Journal of Zoology, 266, 283-91.

Bernard, A., Daux, V., Lécuyer, C., Brugal, J.-P., Genty, D., Wainer, K., Gardien, V., Fourel, F., and Jaubert, J., 2009, Pleistocene seasonal temperature variations recorded in the $\mathrm{d} 18 \mathrm{O}$ of Bison priscus teeth, Earth and Planetary Science Letters, 283, 133-43.

Britton, K., Grimes, V., Dau, J., and Richards, M. P., 2009, Reconstructing faunal migrations using intra-tooth sampling and strontium and oxygen isotope analyses: a case study of modern caribou (Rangifer tarandus granti), Journal of Archaeological Science, 36, 1163-72.

Bryant, J. D., Froelich, P. N., Showers, W. J., and Genna, B. J., 1996a, A tale of two quarries: biologic and taphonomic signatures in the oxygen isotope composition of tooth enamel phosphate from modern and Miocene equids, Palaios, 11, 397-408.

Bryant, J. D., Froelich, P. N., Showers, W. J., and Genna, B. J., 1996b, Biologic and climatic signals in the oxygen isotopic composition of Eocene-Oligocene equid enamel phosphate, Palaeogeography, Palaeoclimatology, Palaeoecology, 126, 75-90.

Fricke, H. C., and O'Neil, J. R., 1996, Inter- and intra-tooth variation in the oxygen isotope composition of mammalian tooth enamel: some implications for paleoclimatological and paleobiological research, Palaeogeography, Palaeoclimatology, Palaeoecology, 126, 91-100.

Gat, J. R., 1980, The isotopes of hydrogen and oxygen in precipitation, in Handbook of environmental isotope geochemistry, vol. 1. The terrestrial environment (eds. P. Fritz and J.-C. Fontes), 21-42, Elsevier Amsterdam.

Henton, E., Meier-Augenstein, W., and Kemp, H. F., 2010, The use of oxygen isotopes in sheep molars to investigate past herding practices at the Neolithic settlement of Catalhöyük, central Anatolia, Archaeometry, 52, 429-49.

Hoppe, K. A., Stover, S. M., Pacoe, J. R., and Amundson, R., 2004, Tooth enamel biomineralization in extant horses: implications for isotopic microsampling, Palaeogeography, Palaeoclimatology, Palaeoecology, 206, 35565.

Koch, P. L., Fisher, D. C., and Dettman, D., 1989, Oxygen isotope variation in the tusks of extinct proboscideans: a measure of season of death and seasonality, Geology, 17, 515-19.

Koch, P. L., Tuross, N., and Fogel, M. L., 1997, The effects of sample treatment and diagenesis on the isotopic integrity of carbonate in biogenic hydroxylapatite, Journal of Archaeological Science, 24, 417-29.

Koch, P. L., Heisinger, J., Moss, C., Carlson, R. W., Fogel, M. L., and Behrensmeyer, A. K., 1995, Isotopic tracking of change of diet and habitat use in African elephants, Science, 267, 1340-3.

Kohn, M., Schoeninger, M. J., and Valley, J. W., 1996, Herbivore tooth oxygen isotope compositions: effects of diet and physiology, Geochimica et Cosmochimica Acta, 60, 3889-96.

Kohn, M., Schoeninger, M. J., and Valley, J. W., 1998, Variability in oxygen compositions of herbivore teeth: reflections of seasonality or developmental physiology? Chemical Geology, 152, 97-112.

Land, L. S., Lundelius, E. L., and Valastro, S., 1980, Isotopic ecology of deer bones, Palaeogeography, Palaeoclimatology, Palaeoecology, 32, 143-51.

Longinelli, A., 1984, Oxygen isotopes in mammal bone phosphate: a new tool for paleohydrological and paleoclimatological research, Geochimica et Cosmochimica Acta, 48, 385-90.

Luz, B., Kolodny, Y., and Horowitz, M., 1984, Fractionation of oxygen isotopes between mammalian bone-phosphate and environmental drinking water, Geochimica et Cosmochimica Acta, 48, 1689-93.

Milhaud, G., and Nézit, J.,1991, Développement des molaires chez le mouton. Etude morphologique, radiographique et microdurométrique, Recueil de Médecine Vétérinaire 167, 121-7.

Nelson, S. V., 2005, Paleoseasonality inferred from equid teeth and intra-tooth isotopic variability, Palaeogeography, Palaeoclimatology, Palaeoecology, 222, 122-44.

Rozanski, K., Araguas-Araguas, L., and Gonfiantini, R., 1993, Isotopic patterns in modern global precipitations, in Climate change in continental isotopic records (eds. P. K. Swart, K. C. Lohman, J. McKenzie and S. Savin), 1-36, American Geophysical Union, Washington, DC.

Sharma, S., Joachimski, M. M., Tobschall, H. J., Singh, I. B., Tewari, D. P., and Tewari, R., 2004, Oxygen isotopes of bovid teeth as archives of paleoclimatic variations in archaeological deposits of the Ganga plain, India, Quaternary Research, 62, 19-28.

Sharp, Z. D., and Cerling, T. E., 1998, Fossil records of seasonal climate and ecology: straight from the horse's mouth, Geology, 26, 219-22.

Stuart-Williams, H. L. Q., and Schwarcz, H. P., 1997, Oxygen isotopic determination of climatic variation using phosphate from beaver bone, tooth enamel and dentine, Geochimica et Cosmochimica Acta, 61, 2539-50.

Suga, S., 1982, Progressive mineralization pattern of developing enamel during the maturation stage, Journal of Dental Research, 61, 1532-42. 
van Dam, J. A., and Reichart, G. J., 2009, Oxygen and carbon isotope signatures in late Neogene horse teeth from Spain and application as temperature and seasonality proxies, Palaeogeography, Palaeoclimatology, Palaeoecology, 274, 64-81.

Vose, R. S., Schmoyer, R. L., Steurer, P. M., Peterson, T. C., Heim, R., Karl, T. R., and Eischeid, J., 1992, The Global Historical Climatology Network: long-term monthly temperature, precipitation, sea level pressure, and station pressure data, Technical Report ORNL/CDIAC-53, NDP-041, Carbon Dioxide Information Analysis Center, Oak Ridge National Laboratory, Oak Ridge, TN.

Weinreb, M. M., and Sharav, D. M. D., 1964, Tooth development in sheep, American Journal of Veterinary Research, 25(107), 891-908.

Zazzo, A., Balasse, M., Passey, B. H., Moloney, A. P., Monahan, F. J., and Schmidt, O., 2010, The isotope record of shortand long-term dietary changes in sheep tooth enamel: implications for quantitative reconstruction of paleodiets, Geochimica et Cosmochimica Acta, 74, 3571-86. 